\title{
Vibriosis vaccination of rainbow trout Salmo gairdneri at varying temperatures and seasons. I. Effects on mortality and feed conversion in four Swedish field trials
}

\author{
Margaret A. Thorburn ${ }^{1, *}$, Tim E. Carpenter ${ }^{1}$, Olle Ljungberg ${ }^{2}$ \\ ${ }^{1}$ Department of Epidemiology and Preventive Medicine, School of Veterinary Medicine, University of California, Davis, \\ California 95616, USA \\ ${ }^{2}$ National Veterinary Institute, Box 7073, S-750 07 Uppsala, Sweden
}

\begin{abstract}
Vibriosis vaccine trials were conducted on 4 Swedish brackish water rainbow trout Salmo gairdneri net-pen farms. Intraperitoneal (IP) vaccination of fall- and spring-transport yearlings at 3 to $16{ }^{\circ} \mathrm{C}$ provided significant protection against mortalities from Vibrio anguillarum, serotype 1 (VA). Dipvaccination of fingerlings provided only slight protection of limited duration. Non-vaccinated trout on one farm had a higher feed conversion ratio (FCR) than corresponding vaccinated trout. However, on 2 other farms, there were no significant differences in the FCRs of non-vaccinated and vaccinated trout. Any benefits of the efficiency of food utilization conferred by vaccination therefore appeared to be farmspecific, but contributing factors were not identified.
\end{abstract}

\section{INTRODUCTION}

Vibriosis is the most prevalent disease in Swedish brackish water rainbow trout Salmo gairdneri farming facilities (Forskningsrådnämnden 1982). In Sweden, mortalities from Vibrio anguillarum have only been positively confirmed during the warmer part of the growing season (approximately mid-June through midOctober). Losses occur, most commonly, in yearling trout during the first growing season following their transport, either in the spring (70 to $200 \mathrm{~g}$ average weight) or the previous autumn ( 40 to $150 \mathrm{~g}$ average weight), from freshwater to brackish water farms.

In initial field trials conducted to assess the efficacy of vibriosis vaccination in Sweden, rainbow trout were vaccinated in the spring by intraperitoneal (IP) injection, after water temperatures had exceeded $10^{\circ} \mathrm{C}$ and 2 to $4 \mathrm{wk}$ prior to transport to brackish water (Ljungberg 1983). These trials gave promising results, but the recommended vaccine protocol has presented serious difficulties for freshwater breeders, due to severe space

\footnotetext{
- Present adress: National Veterinary Institute, Box 7073, S-750 07 Uppsala, Sweden
}

and time shortages in the spring. The purpose of the studies reported in this paper was to investigate alternative vibriosis vaccination procedures suitable to Swedish conditions. Results published from vaccine tests conducted elsewhere were used to help design the various trials.

Based on Horne et al.'s (1982) report of long-term persistence of protection following IP-vaccination of rainbow trout at $6{ }^{\circ} \mathrm{C}$, we chose, in trout destined for spring transport, to test the efficacy of IP-vaccination at winter-time temperatures.

Trout destined for autumn transport, and vaccinated prior to transport, require a vaccine procedure which provides protective immunity of adequate duration. Håstein et al. (1980) reported adequate protection over a 1 yr period in rainbow trout vaccinated shortly before late autumn transport. We tested this procedure in one group of fall-transport trout. We also tested the efficacy of dip-vaccination in the spring in groups subsequentally transported to brackish water in late summer and late autumn.

In one group of autumn transport trout, we waited and vaccinated (IP) trout at the brackish water site, several months after transport, but prior to the seasonal 
fresh and thawed frozen fish by bacteriological culture techniques to determine the cause of death. Kidney material was streaked on blood agar, and isolates were identified with rabbit anti-Vibrio anguillarum serum by the rapid slide agglutination technique.

Exact vibrio-specific mortalities (\%) were not determined because not all of the dead fish were examined bacteriologically. In any given net-pen the vibriospecific mortality was calculated by multiplying the total mortality by the proportion of the sampled dead fish yielding pure cultures of Vibrio anguillarum. Total mortality was calculated as follows:

Number of fish dying in net-pen in period from $3 \mathrm{~d}$ prior to first $V$. anguillarum isolation to $3 \mathrm{~d}$ after

Total mortality decreased to pre-outbreak levels

mortality $=\frac{\text { Number of fish in net-pen at start of outbreak }}{\text { Nortalis }}$

We used a 1-way analysis of variance (ANOVA), followed by the Tukey method of multiple comparisons (Neter \& Wasserman 1974), and a Student's t-test to test for significant $(p<0.05)$ differences in mean vibriosisspecific mortality among non-vaccinated and vaccinated groups on the 2 farms (A, 1985; C) where data from replicate test and control pens were available. The normal approximation to the binomial distribution (Remington \& Schork, 1970) was used to test for significant $(p<0.05)$ differences in vibrio-specific mortality on the remaining farms $(A, 1984 ; B$ and D). Significance results obtained from trials where data were not available from replicate pens should, however, be interpreted with some caution, due to the possible influence of non-quantifiable 'pen-effects' on observed mortaility (Michel et al. 1984).

We calculated feed conversion ratios (FCRs) for the different groups of fish on Farms $A, B$, and $C$ as follows:

Total amount of feed $(\mathrm{kg})$ fed in the period between first and last sample weighings

(Average weight gain per fish $[\mathrm{kg} \mid) \times$ (average number of fish in pen or group)

where (1) 'average weight gain per fish' was based on the difference between the results of the season's first and last sample weighings of ca 100 to 200 fish from each net-pen (Farms B and C) or group (the fish farmer at Farm A only recorded average weight for each group); and (2) the average number of fish in pen or group' was determined by calculating the mean number of fish in successive ca $15 \mathrm{~d}$ periods and taking the mean of all these periods included in the time interval between the first and last sample weighings.

On Farms $A$ and $B$, sample weighings were only conducted twice, once at the start of the growing season and once towards the end of the season. Farm C, however, conducted 7 sample weighings of each netpen at 2 to 3 wk intervals. We used the Farm C data to statistically evaluate the effect of vaccination on growth by constructing a production function based on multiple least squares linear regression analysis (Neter \& Wasserman 1974), In this analysis, weight gain per fish was the dependent variable and degree-days, feed fed per fish, and vaccine status (control, cold-water vaccination or warm-water vaccination) were the independent variables. A significant contribution of vaccine status, either as an individual term (tested with the $t$ statistic, $p<0.05$ ) and/or in interaction with either of the other 2 independent variables (tested with the partial $F$-test, $p<0.05$ ) would indicate that vaccination had a significant effect on growth curves. In particular, significant interactions between vaccine status and feeding rate would denote differences in FCRs among the particular vaccine groups indicated.

\section{RESULTS}

Table 2 presents the estimated mortalities and FCRs for the various trial groups. In all cases of vibriosis the isolated pathogen was exclusively Vibrio anguillarum, serotype 1 (using the serotype classification scheme proposed by Sorensen \& Larsen 1986). As shown, the non-vaccinated groups on Farms B, C and D each underwent one course of oxytetracycline treatment. No vaccinated groups were treated.

The IP-vaccination schemes tested on Farms B's and C's spring-transport trout provided significant levels of protection against vibrio-induced mortality. The trout vaccinated according to the previously recommended protocol on Farms B (V1) and C (V2) remained diseasefree, while corresponding non-vaccinated fish $(B, C 1$ and $\mathrm{C}, \mathrm{C} 1$ ) yielded, despite medication, significantly higher vibrio-specific mortalities of 3.9 and $5.05 \%$ (average percentage), respectively. The trout vaccinated at $3{ }^{\circ} \mathrm{C}$ on Farm C (V1) also had a $0 \%$ vibriosisspecific mortality, which was significantly lower than the average mortality (5.05\%) for the non-vaccinated trout (C, C1).

The fall-transport fish on Farm D, which were IPvaccinated in the spring following transport (V1), remained essentially disease-free (vibrio-specific mortality of at most $0.1 \%$ ) while corresponding non-vaccinated trout had a significantly higher vibrio-specific mortality of $6.5 \%$ despite medication.

Intra-peritoneal vaccination in the fall, prior to transport to brackish water, protected Farm A's fish (V3) against the following summer's vibriosis outbreak. The vibrio-specific mortality of $\mathrm{A}, \mathrm{V} 3(0.3 \%$ or less $)$ was significantly lower than that of the November transport control fish $(\mathrm{C} 2,7.5 \%)$.

Dip-vaccination gave a mild protection of limited duration. Vibriosis occurred in Farm A's summer-transport dip-vaccinated (V1) and non-vaccinated (C1) trout 
Table 2. Estimated vibriosis mortality (\%) and feed conversion ratios (FCRs) for rainbow trout on Swedish brackish water commercial net-pen farms participating in vibriosis vaccine trials, 1984 to 1987

\begin{tabular}{|c|c|c|c|c|c|c|}
\hline \multirow[t]{2}{*}{ Farm } & \multirow[t]{2}{*}{ Group ${ }^{a}$} & \multicolumn{4}{|c|}{ Vibriosis outbreak } & \multirow[t]{2}{*}{$F C R^{b}$} \\
\hline & & $\begin{array}{l}\text { 1st VA isolation } \\
\text { (day/mo) }\end{array}$ & $\begin{array}{l}\text { Total mort. } \\
\quad(\%)\end{array}$ & $\begin{array}{l}\text { Vibriospecific } \\
\text { mort. }^{b}(\%)\end{array}$ & $\begin{array}{l}\text { Anitibiotics fed } \\
\text { (day/mo.) }\end{array}$ & \\
\hline A & V1 & $1 / 10$ & 8.3 & 7.1 & No & ND \\
\hline 1984 & $\mathrm{C} 1$ & $25 / 9$ & 13.8 & 10.7 & $30 / 9-6 / 10$ & ND \\
\hline A & V1. & ND & 1.1 & $\leq 1.1$ & No & ND \\
\hline \multirow{7}{*}{1985} & $\mathrm{C} 1$ & ND & 1.9 & $\leq 1.9$ & No & ND \\
\hline & $\mathrm{V} 2$ & $16 / 7$ & 8.2 & 8.2 & No & \multirow{2}{*}{1.28} \\
\hline & V2 & $16 / 7$ & 5.9 & 5.9 & No & \\
\hline & V3 & ND & 0.3 & $\leq 0.3$ & No & \multirow{2}{*}{1.43} \\
\hline & V3 & ND & 0.3 & $\leq 0.3$ & No & \\
\hline & $C 2$ & $16 / 7$ & 8.0 & 8.0 & No & \multirow{2}{*}{1.48} \\
\hline & $\mathrm{C} 2$ & $16 / 7$ & 7.0 & 7.0 & No & \\
\hline \multirow[t]{4}{*}{$B$} & V1 & - & $<0.1$ & 0.0 & No & 1.68 \\
\hline & V1 & - & $<0.1$ & 0.0 & No & ND \\
\hline & V1 & - & 0.4 & 0.0 & No & 1.49 \\
\hline & $\mathrm{C} 1$ & $28 / 8$ & 3.9 & 3.9 & $30 / 8-7 / 9$ & 2.65 \\
\hline \multirow[t]{6}{*}{$\mathrm{C}$} & V1 & - & $<0.1$ & 0.0 & No & 1.23 \\
\hline & V1 & - & $<0.1$ & 0.0 & No & 1.11 \\
\hline & $V_{1}$ & - & $<0.1$ & 0.0 & No & 1.37 \\
\hline & V2 & - & $<0.1$ & 0.0 & No & 1.40 \\
\hline & $\mathrm{C} 1$ & $26 / 8$ & 3.3 & 1.9 & $30 / 8-9 / 10$ & 1.31 \\
\hline & $\mathrm{C} 1$ & $26 / 8$ & 8.2 & 8.2 & $30 / 8-9 / 10$ & 1.50 \\
\hline \multirow[t]{3}{*}{$\mathrm{D}$} & V1 & $\mathrm{ND}$ & 0.1 & $\leq 0.1$ & No & ND \\
\hline & V1 & ND & 0.1 & $\leq 0.1$ & No & ND \\
\hline & $\mathrm{C} 1$ & $19 / 8$ & 6.5 & 6.5 & $1 / 9-7 / 9$ & $N D$ \\
\hline \multicolumn{7}{|c|}{$\begin{array}{l}\text { VA: Vibrio anguillarum; ND: not done; -: all culture results negative } \\
\text { a Groups are described in Table } 1\end{array}$} \\
\hline
\end{tabular}

ca 4 mo after the dip-vaccination. The vibrio-specific mortality of V1 $(7.1 \%)$ was significantly lower than that of $\mathrm{C} 1$ (10.7\% despite antibiotic therapy). The dipvaccinated fish (V2) transported to Farm $A$ in November (after the 1984 outbreak) experienced, the following summer (1985), an average vibrio-specific mortality of $7.05 \%$, which did not differ significantly from that of the corresponding control fish $(\mathrm{C} 2,7.5 \%)$, but was significantly higher than that of the IP-vaccinates (V3, $0.3 \%$ ).

The survivors of Farm A's 1984 vibriosis outbreak, Groups A, C1 and A. V1, appeared quite resistant to vibriosis the second summer. The 1985 vibrio-specific mortalities for these groups (at most, $1.9 \%$ and $1.1 \%$, respectively) were substantially lower than the average mortalities of their non-exposed cohorts (A, C2: $7.5 \%$ and $\mathrm{A}, \mathrm{V} 2: 7,05 \%$ ).

Vaccination was obviously associated with increased feed conversion efficiency on Farm B only, where nonvaccinated fish had a much higher FCR (2.65) than did corresponding vaccinated fish (average FCR $=1.59$ ). Feed conversion ratios among cold-water vaccinates
(V1) on Farm $C$ were, on the average, slightly lower than those of the other (warm-water vaccinated, V2, and control, C1) fish. The selected production function (adjusted $R^{2}=0.969$ ) did not, however, include vaccine status, indicating that there were no significant differences among the FCRs or among the growth curves, given constant feeding rates, of the 3 groups.

\section{DISCUSSION}

All of the IP-vaccination schemes tested in these trials protected fish against vibriosis during their first 'high-risk' growing season in brackish water It is particularly noteworthy that vaccine injected at very low temperatures $\left(3^{\circ} \mathrm{C}\right.$, Farm $\mathrm{C}$ ) provided good protection. Since vaccination at lower temperatures has been associated with delays in the immune response of salmonids (Groberg 1982), the cold-water trial trout were vaccinated more than $5 \mathrm{wk}$ before transport (and, as it turned out, $16 \mathrm{wk}$ before the vibriosis outbreak in 
controls). These fish were apparently allowed sufficient time to mount an effective immune resonse.

Dip-vaccination provided some protection against vibriosis, but the protection was mild and of limited duration. Protection against vibriosis is stronger in fingerlings vaccinated at larger sizes (Thorburn \& Jansson 1988). Furthermore, trout dip-vaccinated at $4.5 \mathrm{~g}$ or larger remain protected longer than those vaccinated at $2.3 \mathrm{~g}$ (Johnson et al. 1982). The $2.3 \mathrm{~g}$ vaccinated Farm $C$ trout were not able to mount an immune response which in strength and/or duration very effectively resisted natural challenge. It would be worthwhile, however, to test whether dip-vaccination of larger fingerlings would provide adequate protection for autumn-transport yearling trout in Sweden.

The Farm A trout which survived the 1984 vibriosis outbreak (C1 and V1) apparently gained some immunity from natural 'outbreak-level' exposure, as shown, the following summer, by their low mortaility rates relative to non-outbreak-exposed cohorts (C2 and V2). This is consistent with the findings of Evelyn \& Ketcheson (1980) for pen-reared sockeye salmon Oncorhyncus nerka. The immunity elicited by exposure, alone (C1) or following dip-vaccination (V1), appeared, however, to provide somewhat less protection than did that elicited by IP-vaccination (V3).

Previous investigations into possible growth effects of vibriosis vaccination have reported conflicting results. Antipa \& Amend (1977) found no significant differences in the growth rates of vaccinated and nonvaccinated coho salmon in a vibriosis vaccine trial. Sawyer \& Strout (1977), on the other hand, reported improved growth of coho salmon vaccinated against vibriosis, as compared to medicated and non-medicated controls, in one field trial. These 2 reports did not present feed conversion ratios

In the present study, vaccination was associated with markedly increased efficiency in feed utilization on only 1 of 3 farms (Farm B) surveyed. Because there was no replication of the control pen on the farm (B) where the FCR effect was noted, this result should be interpreted cautiously. The magnitude of the difference was large enough, however, to cause us to wonder whether there might not be farm-specific practices or conditions that interact with vaccination to bring about such results. If so, it would be worthwhile identifying these factors.
Acknowledgements. This work was supported by funds provided by the USDA Animal Health Act of 1977 (P. L. 95-113) and administered through the LDRL of the School of Veterinary Medicine, University of California, Davis; and by the Swedish Council for Forestry and Agricultural Research (981-84; V18:2). The support is gratefully acknowledged.

\section{LITERATURE CITED}

Antipa, R., Amend, D. F. (1977). Immunization of Pacific salmon: comparison of intraperitoneal injection and hyperosmotic infiltration of Vibrio anguillarum and Aeromonas salmonicida bacterins. J. Fish. Res. Bd Can. 34: 203-208

Evelyn, T. P. T., Ketcheson, J. E. (1980). Laboratory and field observations on antivibriosis vaccines. In: Ahne, W. (ed.) Fish diseases. Third COPRAQ session. Springer-Verlag, Berlin, p. 46-52

Forskningsrådsnämnden (1982). Pigg som en mort: vattenbrukets hälso och sjukdomsfragor ('Aquaculture's health and disease questions'). Rapport 82:8, Stockholm, p. 32-33

Groberg, W J. (1982). Infection and the immune response induced by Vibrio anguillarum in juvenile coho salmon (Oncorhyncus kisutch). Ph. D. thesis, Oregon State University, Corvallis

Håstein, T., Hallingstad, F., Refstie, T., Roald, S. O. (1980) Recent experience of field vaccination trials against vibriosis in rainbow trout (Salmo gairdneri). In: Ahne, W. (ed.) Fish diseases. Third COPRAQ-session. Springer-Verlag, Berlin, p. 53-59

Horne, M. T., Tatner, M., McDermont, S., Agius, C., Ward, P. (1982). Vaccination of rainbow trout, Salmo gairdneri Richardson, at low temperatures and the long-term persistence of protection. J. Fish Dis. 5: 343-345

Johnson, K. A., Flynn, J. K., Amend, D. F. (1982). Duration of immunity in salmonids vaccinated by direct immersion with Yersinia ruckeri and Vibrio anguillarum bacterins. J. Fish. Dis. 5: 207-213

Ljungberg, O. (1983). Vaccination mot vibrios ('Vaccination against vibriosis'). Vattenbruk $1: 7$

Michel, C., Tixier, G., Mevel, M. (1984). An assessment of the potency and economic value of fish vaccines. In: de Kinkelin, P. (ed.) Symposium on Fish Vaccination, Paris, Feb 20-22, 1984. Office International des Epizooties, p. 75-96

Neter, J., Wasserman, W. (1974). Applied linear statistical models. Richard D. Irwin, Inc., Homewood, Illinois

Remington, R. D., Schork, M. A. (1970). Statistics with applications to the biological and health sciences. Prentice-Hall, Inc., Englewood Cliffs

Sawyer, E. S., Strout, R. G. (1977). Survival and growth of vaccinated, medicated and untreated coho salmon (Oncorhyncus kisutch) exposed to Vibrio anguillarum. Aquaculture 10: 311-315

Sorensen, U. B. S., Larsen, J. L. (1986). Serotyping of Vibrio anguillarum. Appl environ. Micriobiol. 51: 593-597

Thorburn, M. A., Jansson, E. (1988). The effects of booster vaccination and fish size on survival and antibody production following Vibrio infection of bath-vaccinated rainbow trout, Salmo gairdneri. Aquaculture 71: 285-291 